\title{
TRENDS IN LEGAL SCHOLARSHIP: A STATISTICAL STUDY
}

\author{
ROBERT C. ELLICKSON*
}

\begin{abstract}
This study tracks the appeal of various intellectual approaches to legal scholars during the period 1982-96. Fifteen different approaches were paired with one or more proxies consisting of a word or phrase. Searches were conducted in a Westlaw database that contains full texts of law review documents to determine trends in the appearance of these proxies. A method was devised for neutralizing distortions attributable to changes in database size over time. Among the findings are little or no decline in doctrinal analysis, a modest rise in law and economics, and a boom and subsequent bust in Critical Legal Studies. Leading law reviews have been unusually prone to publish works that refer to civic republicanism, Critical Legal Studies, Critical Race Theory, and social norms.
\end{abstract}

$\mathrm{C}$ ITATION analysts generally have sought to tally references to scholars, faculties, journals, and discrete works of scholarship. ${ }^{1}$ This study, by contrast, presents a simple technique for quantifying trends in references to ideas and scholarly approaches. The results presented were generated through searches of the contents of a Westlaw electronic database, Journals and Law Reviews (JLR), for the years 1982-96. I test, among other propositions, whether law journals have been shifting away from doctrinal scholarship, whether the field of law and economics has been rising or falling, and whether Critical Legal Studies is dead. The study makes two contributions to the literature on citations. The first is to illustrate the potential of using a simple linguistic proxy for a complex idea or approach. The second is to provide a deflator to neutralize the huge growth of the JLR database over time, thus helping to expose changes in real citation rates.

I start with a brief outline of my methods. The basic results of the investi-

* Walter E. Meyer Professor of Property and Urban Law, Yale Law School. Thanks to Ian Ayres, Brian Leiter, and Fred Shapiro for suggestions and to Laura Storto for invaluable research assistance.

'See, for example, the works published in this symposium and in Symposium on Trends in Legal Scholarship, 71 Chi.-Kent L. Rev. 743 (1996).

[Journal of Legal Studies, vol. XXIX (January 2000)]

(C) 2000 by The University of Chicago. All rights reserved. 0047-2530/2000/2901-0023\$01.50 
gations then are presented in 11 tables. Because many of the entries warrant little or no elaboration, the text describing most tables is terse. The last section of the article systematically addresses the issue of whether leading law journals feature certain ideas and approaches more than other law journals do. That comparison can help reveal how ideas diffuse and how intellectual bandwagons start and end.

\section{A Method for Tracing Intellectual TRENDS IN LEgal SCHOLARSHIP}

The techniques presented here could be employed to measure the rise and fall of intellectual approaches among judges, legislators, journalists, or any other set of authors whose works are collected in an electronic database. I start, however, by measuring only trends in the writings of authors whose works are included in JLR. In 1999 JLR contained documents from over 600 law-related periodicals. ${ }^{2}$ (Document is Westlaw's generic term for a piece of law review writing - an article, student note, book review, or whatever.) Most JLR documents are published by law-school-affiliated organizations. Another Westlaw database, LAWPRAC, contains most bar association journals. ${ }^{3}$ It is believed that ideas tend to originate in the academy and then diffuse into practice. ${ }^{4}$ If so, this study, based as it is on JLR, should be revealing the leading edge of legal thought.

\section{A. Selecting a Search Term to Serve as a Proxy for an Idea or Approach}

A citation analyst who seeks to discern whether a particular idea is rising or falling over time must surmount two basic hurdles. The first is to identify words or phrases that are plausible proxies for the (usually more complex)

\footnotetext{
2 To obtain an on-line listing of the journals included in a Westlaw database, open that database and enter the Scope command. For details of when JLR starts to cover some or all of a particular journal's documents, either enter the Scope command when in that journal's individual database or consult the hard-copy Westlaw Database Directory.

${ }^{3}$ Some Westlaw placements of periodicals are puzzling. For instance, Westlaw includes the ABA Journal in LAWPRAC but places the Real Property, Probate, and Trust Journal, a publication of an ABA section, in JLR. In general, the percentage of practitioner-oriented publications in JLR has increased over time. It began to include Practising Law Institute documents in September 1984, and ALI-ABA documents in 1988. Westlaw combines JLR and LAWPRAC into a larger database, TP-ALL. Some citation analysts have used TP-ALL as their primary source of data. See, for example, Theodore Eisenberg \& Martin T. Wells, Ranking and Explaining the Scholarly Impact of Law Schools, 27 J. Legal Stud. 373 (1998).

${ }^{4}$ See William M. Landes \& Richard A. Posner, The Influence of Economics on Law: A Quantitative Study, 36 J. Law \& Econ. 385, 387 (1993).
} 
idea or analytic approach under examination. For this study, for example, I chose to use estop! as one of the proxies for "'old doctrine," deconstruct! as one for "postmodernism," and James Madison as one for "history.", A good proxy is neither more nor less faddish than the larger approach that it stands for. Because this equivalence is impossible to predict, my selections inherently had to be largely intuitive. To help prevent selection bias, however, I chose each proxy before knowing the deflated time trend associated with it. Because no proxy is perfect, for a majority of the approaches I chose several and aggregated the results. In Table 1 below, for instance, the index showing trends in references to estop! is averaged with the indexes for three other proxies to generate an overall index for trends in references to "old doctrine."

The tables show search results for a total of 35 different proxies, grouped under 15 headings that each denote an intellectual approach. Many other proxies were investigated but ultimately rejected because they generated either too many false negatives or too many false positives. With rare exceptions, ${ }^{6}$ I required that a term receive at least 500 citations in 1994-96. This floor disqualified, for example, the use of thick description as a proxy for work in the law and society vein. To protect against false positives, I examined the full texts of the first several dozen documents citing a potential proxy to test whether in at least 90 percent of its appearances the proxy was serving the function intended. This precaution eliminated many plausible candidates. Sampling revealed, for instance, that $C L S$ is not a reliable indicator of Critical Legal Studies because cls. commonly appears as an abbreviation for the clauses of a constitution.

An important detail: to greatly reduce computational burdens, the tables that follow are based on the number of documents that contain particular proxies, not on the number of proxies appearing in documents. The index for historical approaches thus accords the same weight to a document with one James Madison as to one with 20 James Madisons.

My methods have obvious limitations. Proxies better than the ones chosen may be available. For some of the intellectual approaches, a larger num-

5 The tables' references to proxies exactly replicate the queries employed in the JLR searches. In Westlaw, an exclamation point (!) serves as a root expander; hence a search for estop! picks up documents containing any of the following: estop, estops, estopped, estoppel, and any other word beginning with those five letters. A multiword proxy such as James Madison denotes that the search was conducted for that entire phrase (by means of the query "James Madison'). Hereafter, I assume that readers possess a basic knowledge of how Westlaw searches are conducted.

${ }^{6}$ Most notably, intersectionality, a term used as a marker for Critical Race Theory, an ascendent movement. 


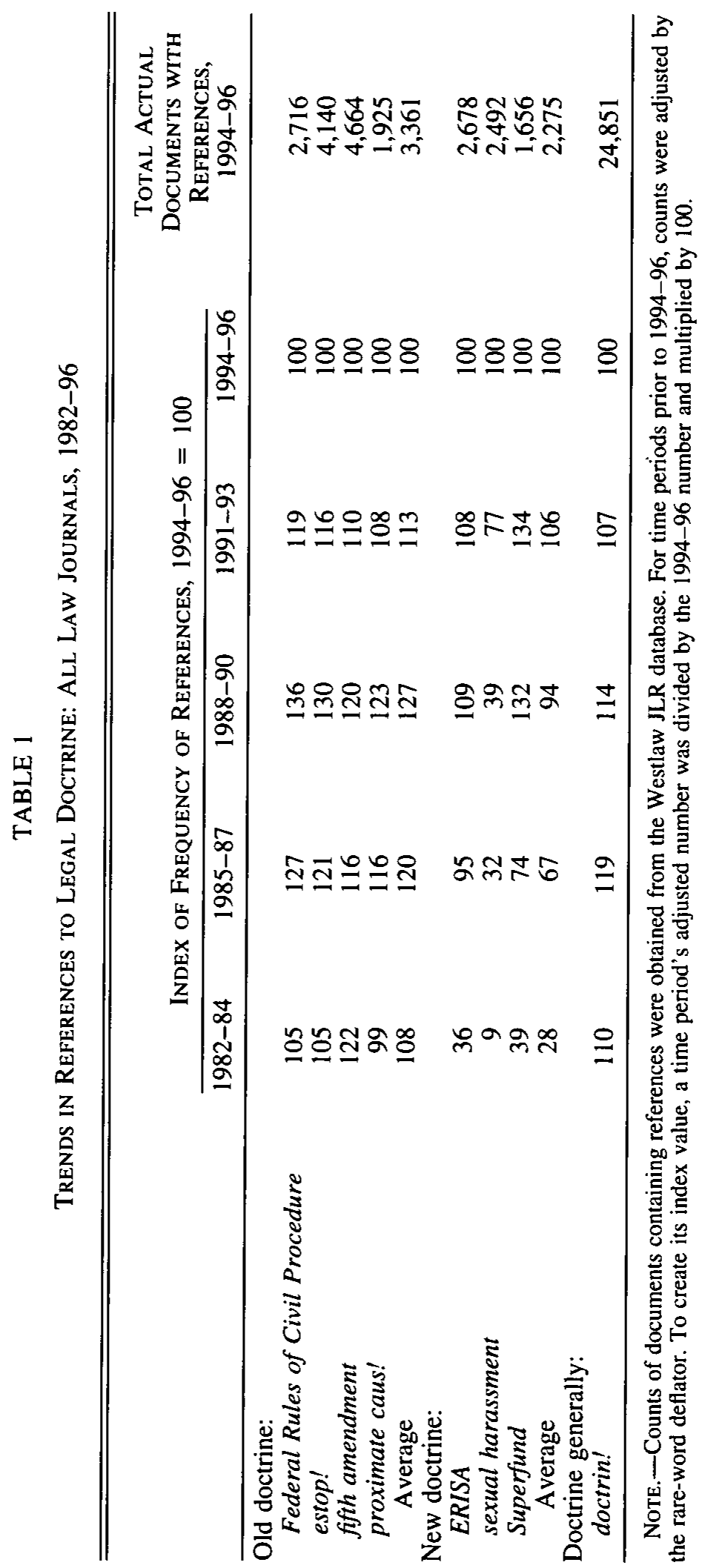


ber of proxies would enhance confidence in the results. (Indeed for five of the intellectual approaches-Critical Legal Studies, social norms, sociology, psychology, and civic republicanism-I use only a single proxy.) Nevertheless, the methodology developed here has merit as long as some word or phrase is capable of serving as a marker for a complex intellectual approach.

\section{B. Adjusting for Changes in a Database's Size over Time}

Because Westlaw's JLR database contains few documents published prior to 1982 , this study had to be confined to law journal citation practices during 1982-96. The tables report trends, over the course of those 15 years, in the number of JLR documents that contain the various proxies. Most of the tables display the findings in columns denoting five sequential 3-year subperiods-1982-84, 1985-87, and so on.

By themselves, trends in actual counts of documents referring to the various proxies would be highly misleading. Between 1982 and 1996 JLR's coverage dramatically changes in both size and composition. During the earlier years JLR includes documents from only about 100 law journals, mainly the most-cited ones. ${ }^{7}$ By 1996 JLR's coverage has ballooned to over 600 publications. Moreover, when Westlaw adds a journal to JLR, for several years it may offer only "selected coverage" of the contents-perhaps only the journal's "articles." For almost all journals, by 1994 JLR has moved to full coverage, thereby adding student notes, book reviews, and other miscellany to the database. An example can illustrate the combined effects of these changes. In 1982 JLR fully covers the contents of only two Harvard Law School journals (the Harvard Law Review and the Harvard Civil Rights-Civil Liberties Law Review); in 1996 it fully covers 11 of Harvard's legal journals.

As a result of these twin sources of change, the number of documents in the JLR database increases from 7,823 in 1982-84 to 71,358 in 1994-96, or roughly ninefold. ${ }^{8}$ In the absence of a deflator that neutralized the effects of JLR's growth, a report of trends in the number of documents containing

${ }^{7}$ In the early years of Westlaw the editors of some selective law journals declined to make their documents electronically available. For example, this is why JLR's coverage of the Journal of Legal Studies does not commence until 1993, a relatively late date.

${ }^{8}$ See Table A1. Additional complications arise because Westlaw can add material retrospectively. For example, in 2000 it could decide to add documents published in 1982-96 in some previously uncovered journal. As a result, someone who seeks to replicate this study's results may come up with absolute numbers slightly larger than the ones I gathered during the early part of 1999 . 
various ideas misleadingly would indicate that virtually all ideas had been sharply on the rise during 1982-96. I therefore devoted significant effort to devising a deflator. ${ }^{9}$ If the character of the average JLR document had not changed over time, a simple deflator based on the trend in the absolute number of JLR documents would suffice. But over time the JLR database changes not only in size but also in composition. As just noted, as the years pass a JLR document is increasingly likely to have appeared in a rarely cited journal or in a practitioner's journal, to have a student author, and so on. In general, as the years pass JLR documents become shorter and less theoretical. ${ }^{10}$ This trend compelled me to experiment with a number of deflators designed to measure the trend in the number JLR documents that are "concept laden." As the Appendix explains in more detail, I ultimately decided to apply a "rare-word deflator" to adjust the number of documents found in a particular subperiod. This rare-word deflator is based on the trend in the number of JLR documents containing 10 selected, and substantively neutral, ordinary English words that authors seldom use. According to the rare-word deflator, the number of concept-laden documents in JLR increases about sixfold between 1982-84 and 1994-96, significantly less than the ninefold increase in total JLR documents.

The tables that appear below generally display indexes that portray how often documents containing a particular proxy for an idea appear in JLR in each of the five time slots. An illustration will help illuminate how these indexes were derived. The right-most column in Table 1 indicates that estop! appears in 4,140 JLR documents that were published in 1994-96. The entries for estop! in the five columns under the various time slots in Table 1 were computed by (1) searching Westlaw in the relevant time period for the absolute number of JLR documents containing estop!, (2) adjusting all numbers prior to 1994-96 by the rare-word deflator, (3) dividing the adjusted number by the absolute number of 1994-96 references (in the case of estop!, by 4,140 ), and (4) multiplying by 100 . This procedure generates

${ }^{9}$ Legal citologists have grappled with this problem in other contexts. See Ian Ayres \& Frederick E. Vars, Determinants of Citations to Articles in Elite Law Reviews, in this issue, at 427 (controlling for changes in size of SSCI database); Eisenberg \& Wells, supra note 3, at 385 (constructing deflator to adjust data obtained in searches conducted on different days).

${ }^{10}$ A random sample of 50-60 documents was drawn for each 3-year time slot. The following table indicates the mean and median lengths, in Westlaw pages, of documents in these samples. Observe that the median length of documents falls continuously and is halved between 1982-84 and 1994-96.

\begin{tabular}{lccccc}
\hline \hline & $1982-84$ & $1985-87$ & $1988-90$ & $1991-93$ & $1994-96$ \\
\hline Mean length (pp.) & 71 & 59 & 48 & 52 & 48 \\
Median length (pp.) & 63 & 48 & 40 & 33 & 32 \\
\hline
\end{tabular}


for all proxies an index value of 100 in the column for 1994-96. The purpose of this elaborate procedure is to ease comparison of the trajectories of various ideas.

\section{TRends in LaW Journal References to VARIOUS LEgAL IDEAS AND APPROACHES}

\section{A. Doctrinal Analysis}

In 1992 Judge Harry Edwards famously asserted that law professors had become overly enamored with "abstract theory" and were failing to produce scholarship useful to judges and practitioners. ${ }^{11}$ Citation analysts similarly have reported that legal scholars have been abandoning doctrinal analysis in order to engage in various sorts of "law and" endeavors. ${ }^{12}$ No one disputes that "law and" work has increased markedly since the mid$1960 \mathrm{~s},{ }^{13}$ and indeed the findings presented later in this study indicate that most varieties continued to blossom after 1982. However, the data in Table 1 cast great doubt on the notion that law journal articles became significantly less doctrinal in the period between 1982 and 1996.

The rows in Table 1 display the eight proxies used as markers for doctrinal analysis. There are four for "old doctrine" (Federal Rules of Civil Procedure, estop!, fifth amendment, proximate caus!), three for "new doctrine" (ERISA, sexual harassment, Superfund),${ }^{14}$ and one for doctrine in general ("doctrin!').

Time trends in the markers for scholarship on "old doctrine" are mixed, but hardly suggestive of any precipitous decline. After deflation, references to fifth amendment did fall by one-sixth between 1982-84 and 1994-96, but references to the three other proxies remained essentially unchanged. Indeed the data indicate a temporary uptick in "old doctrinal" work in the middle portion of the period studied.

"Harry T. Edwards, The Growing Disjunction between Legal Education and the Legal Profession, 91 Mich. L. Rev. 34 (1992). Judge Edwards's article sparked many responses, some of which are collected in Symposium: Legal Education, 91 Mich. L. Rev. 1921 (1993). See also John H. Langbein, Scholarly and Professional Objectives in Legal Education: American Trends and English Comparisons, in What Are Law Schools For? 1, 5-6 (P. B. H. Birks ed. 1996) (asserting a deep decline in doctrinal scholarship in the United States, particularly in the leading journals).

${ }^{12}$ See, for example, Landes \& Posner, supra note 4, at 399, 424 (surveying trends in 1976-90).

${ }^{13}$ See Richard A. Posner, The Decline of Law as an Autonomous Discipline: 1962-1987, 100 Harv. L. Rev. 761 (1987). 96.

${ }^{14}$ These three youthful areas of mostly statutory law were rapidly evolving during 1982- 
As legal scholars increasingly master old doctrinal problems, they can be expected to turn their attention to new ones. And Table 1 indicates that they do. The aggregate index for the three new-doctrine proxies almost quadruples between 1982-84 and 1994-96. Judge Edwards can take some comfort from the fact that the number of JLR documents published in 1994-96 referring to ERISA $(2,678)$ almost equals the number referring to law +2 economic! $(3,126)$ and to feminis! $(3,298) .{ }^{15}$ Moreover, the (deflated) number of documents mentioning doctrin! was virtually flat over the 15-year period. Note also that doctrin! appears in almost 25,000 JLR documents published in 1994-96 (more than one out of three). It is possible, of course, that doctrinal analysis did plummet prior to 1982, the start of the period covered in this study. ${ }^{16}$ If so, Table 1 suggests that there was little or no further bleeding thereafter. In the aggregate, the results of the present study suggest that "law and" approaches are being used as methods to enrich the analysis of doctrine, not as substitutes for it.

\section{B. Law and Economics}

Law and economics indisputably has caused a major intellectual stir within the legal academy. There has been sharp disagreement, however, about the trajectory of this interdisciplinary approach after its upward spurt in 1960-75. William Landes and Richard Posner, after examining a wide variety of citation trends, concluded that "the influence of economics on law was growing at least through the 1980s," 17 the last decade that they analyzed. By contrast I argued in a prior article, on the basis of scantier quantitative analysis, that by the 1980s law and economics was in "steadystate" within law schools. ${ }^{18}$ For their part, skeptics of law and economics long have been anticipating its decline. ${ }^{19}$

To help resolve this debate, six proxies were employed to expose the

15 See the relevant entries in the right-most columns of Tables 1,2 , and 3.

${ }^{16}$ For evidence that doctrinal scholarship in fact was better received in the period prior to the 1980s, see William M. Landes \& Richard A. Posner, Heavily Cited Articles in Law, 71 Chi.-Kent L. Rev. 825, 829-30 (1996) (asserting that on Fred Shapiro's lists doctrinal articles constitute 60 percent of the most cited articles of all time but only 26 percent of the most cited articles in the years 1982-1991); Landes \& Posner, supra note 4, at 399 (noting decline after 1976-80 in percentage of leading law review articles that are doctrinal).

${ }^{17}$ Landes \& Posner, supra note 4, at 424. For a review of the literature on the issue, see id. at 388-89.

${ }^{18}$ Robert C. Ellickson, Bringing Culture and Human Frailty to Rational Actors: A Critique of Classical Law and Economics, 65 Chi.-Kent L. Rev. 23, 26-34 (1989). I did not intend this as a slight: "In the fickle world of ideas, it should be stressed, steady-state is a notable achievement." Id. at 32.

${ }^{19}$ See Owen M. Fiss, The Law Regained, 74 Cornell L. Rev. 245, 245 (1989) (surmising that law and economics had "peaked"); Morton J. Horwitz, Law and Economics: Science or Politics? 8 Hofstra L. Rev. 905, 905 (1980) (asserting that economic analysis of law had "peaked out"). 
trend from 1982 to 1996 in (deflated) references to law-and-economic concepts in law journals. Table 2 presents the results. One proxy (risk-avers!) exhibits a slight falloff, but each of the other five rises by an even greater percentage. Indeed, the indexes for two of the proxies-game theor! and human capital-more than double between 1982-84 and 1994-96. The average of the indexes for all six proxies increases from 75 in 198284 to 100 in 1994-96. On the whole, law and economics seems to have been slowly gaining yet more ground in law reviews, particularly during 1991-96.

\section{Antiestablishment Approaches}

Table 3 portrays trends in references to proxies for four somewhat related schools of antiestablishment thought: Critical Legal Studies (CLS), Critical Race Theory, postmodernism, and feminist jurisprudence. Authors of several prior studies have remarked on the surge in citations to works using these approaches. ${ }^{20}$ All took root after 1970, and indeed the phrase critical race theory rarely was used prior to 1990 .

The most striking pattern in Table 3 is the rise and fall of Critical Legal Studies. ${ }^{21}$ The index number for that phrase increases from 72 in 1982-84 to 137 in $1988-90$, but then falls to 100 by $1994-96 .^{22}$ None of the other 34 proxies employed in this article booms and busts in this fashion. In personal conversations, critical legal scholars admit the decline of the movement and attribute it to the advent of "identity politics." Consistent with this theory, the subsequent rows in Table 3 demonstrate the rise of Critical Race Theory in 1988-96 and of feminist jurisprudence throughout 1982-96. After 1990 these two intellectual movements probably did siphon off potential sympathizers from CLS, a movement whose most prominent leaders had been white males.

References to CLS may have declined for other reasons, however. The CLS notion of the inherent indeterminacy of law, for instance, conceivably might have been so widely embraced that its source in CLS scholarship came to be obliterated. Alternatively, perceived shortcomings in the CLS approach may have caused scholars to jettison it. The Marxist strand of

\footnotetext{
${ }^{20}$ Landes \& Posner, supra note 4, at 413-16; Fred R. Shapiro, The Most-Cited Law Review Articles Revisited, 71 Chi.-Kent L. Rev. 751, 758-59 (1996) (discussing leap in "outsider"' scholarship).

${ }^{21}$ Duncan Kennedy, one of the stalwarts of Critical Legal Studies, occasionally has stated that the CLS movement is "dead." See, for example, his remarks at the Yale Legal Theory Workshop, December 19, 1996. Table 3 indicates that "in sharp decline" would be more accurate. But compare Duncan Kennedy, A Critique of Adjudication 8-10 (1997) (asserting that CLS "came apart" as a social movement in the late 1980s but that it continues to have vitality as an academic school and a theory of law).

${ }^{22}$ The falloff is even sharper in leading law journals. See infra Section IIIB.
} 


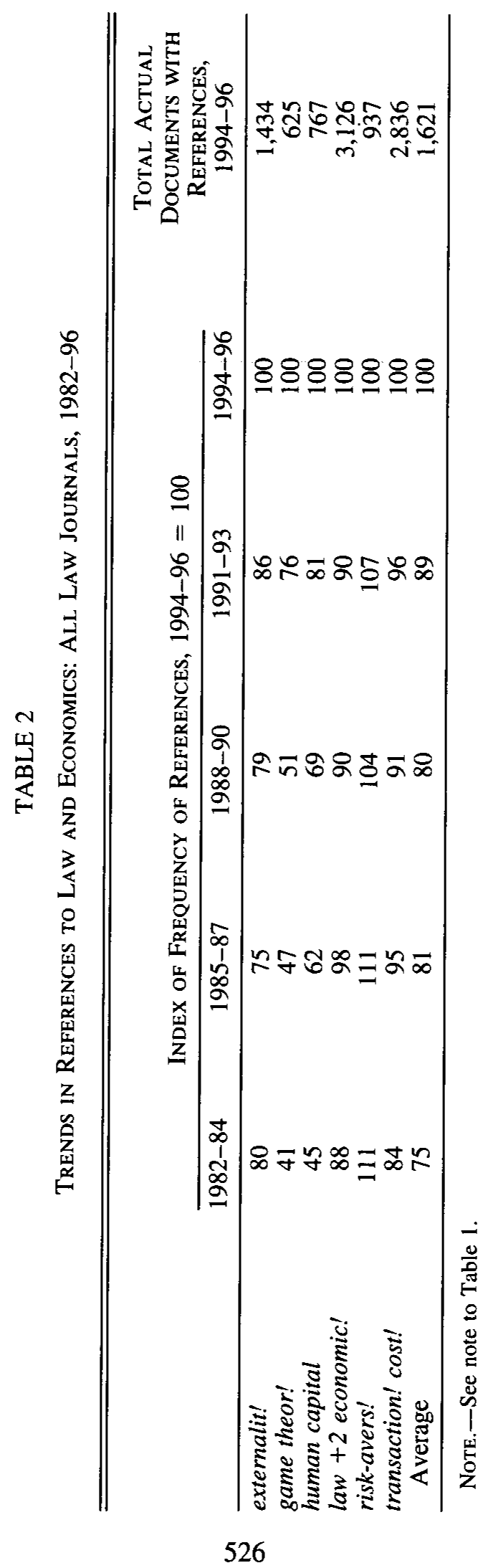

HeinOnline -- 29 J. Legal Stud. 5262000 


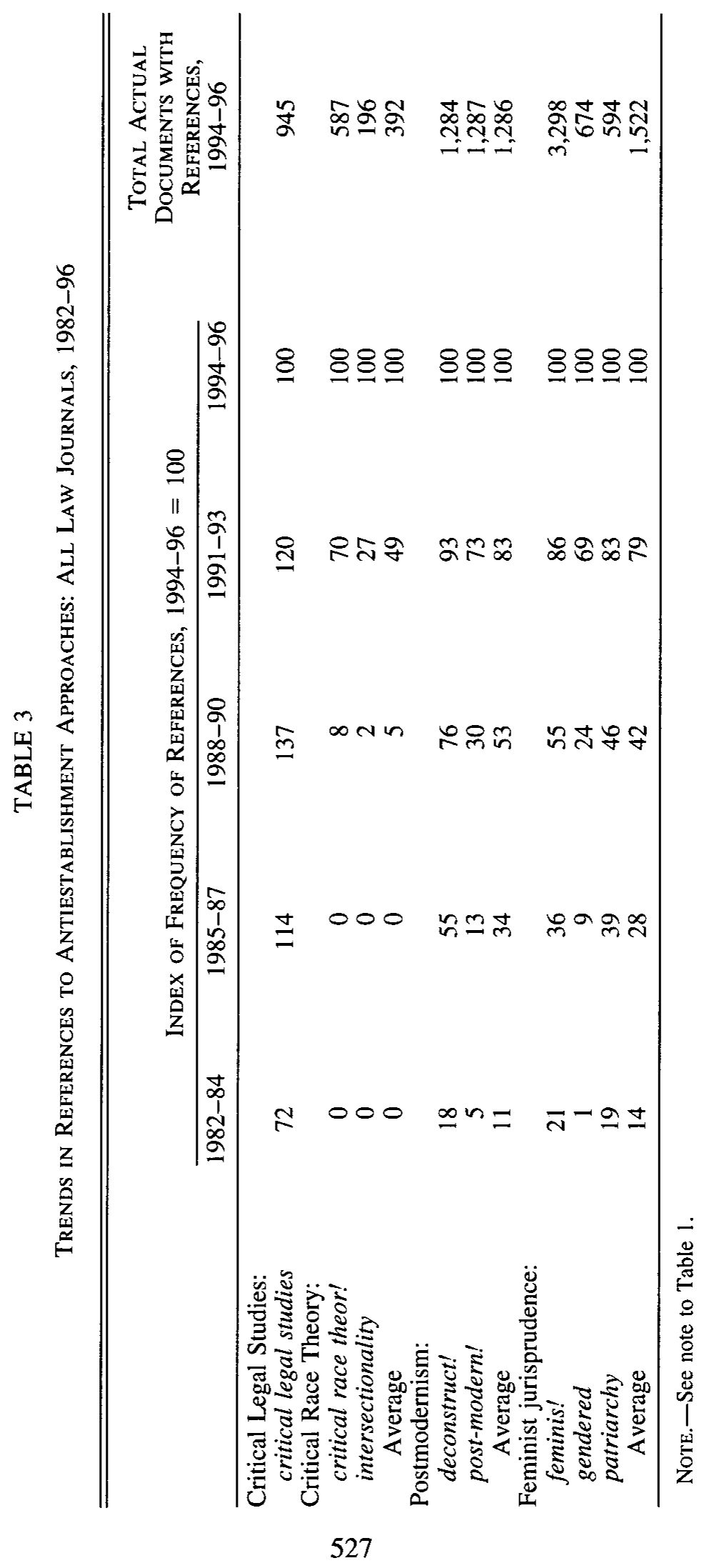

HeinOnline -- 29 J. Legal Stud. 5272000 
CLS, in particular, undoubtedly became less credible after 1989 with the eclipse of communism in Eastern Europe and the Soviet Union. ${ }^{23}$ The data in Table 3 are not adequate to enable an observer to judge the relative plausibility of these competing theories.

Table 3 indicates that the rates of increase in references to postmodernism and feminist jurisprudence, although still positive, slowed after their boom years in 1982-93. It is too early to tell whether this loss of momentum is temporary or whether these movements are starting to plateau.

\section{Empirical and Sociological Approaches}

Several intellectual historians have asserted that social-scientific work has "not caught on" in the American legal academy. ${ }^{24}$ To test this proposition Table 4 displays trends in law journal references to proxies for several traditional forms of social-scientific work.

As Table 4 indicates, in 1994-96 empiric! appeared in 8,739 JLR documents, more than six times the number that contained post-modern!, ${ }^{25}$ a proxy for skepticism about empiricism. The indexes for both empiric! and quantitat!, however, are virtually flat from 1982 to 1996 . This indicates that law journal authors have not been becoming more inclined to cite others' empirical work. On the other hand, the indexes for both statistic! significan! and Table 1 almost double over the same time frame. These latter terms would be relatively likely to appear in a document presenting original empirical work. The data in Table 4 thus hint that law professors and students have become more inclined to produce (although not to consume) quantitative analyses. Postmodernism may be ascending, but so too is number crunching. This symposium itself is another straw in the wind!

What about trends in social-scientific approaches other than law and economics (the subject of Table 2)? The bottom several rows of Table 4 indicate that as the 1990s progressed authors of law journal documents became somewhat more likely to refer to social phenomena. The indexes both for

\footnotetext{
${ }^{23}$ For discussion of Marxist and neo-Marxist elements in CLS thought, see Donald F. Brosnan, Serious but Not Critical, 60 S. Cal. L. Rev. 259, 271 (1987).

${ }^{24}$ See Neil Duxbury, Patterns of American Jurisprudence 445 (1995) ("Law and Society scholarship never really caught on in American law schools"); John Henry Schlegel, American Legal Realism and Empirical Social Science 252 (1995) ("Why has empirical legal research not caught on, not taken hold, in the law schools?'); see generally id. at 238-52 (identifying the University of Wisconsin Law School as a partial exception). See also Peter Schuck, Why Don't Law Professors Do More Empirical Research? 39 J. Legal Educ. 323 (1989); see, generally, Symposium: Social Science in Legal Education, 35 J. Legal Educ. 465 (1985).

${ }^{25}$ See Table 3. In Westlaw a search for post-moderm! also picks up the variants postmodern! and post modern!.
} 


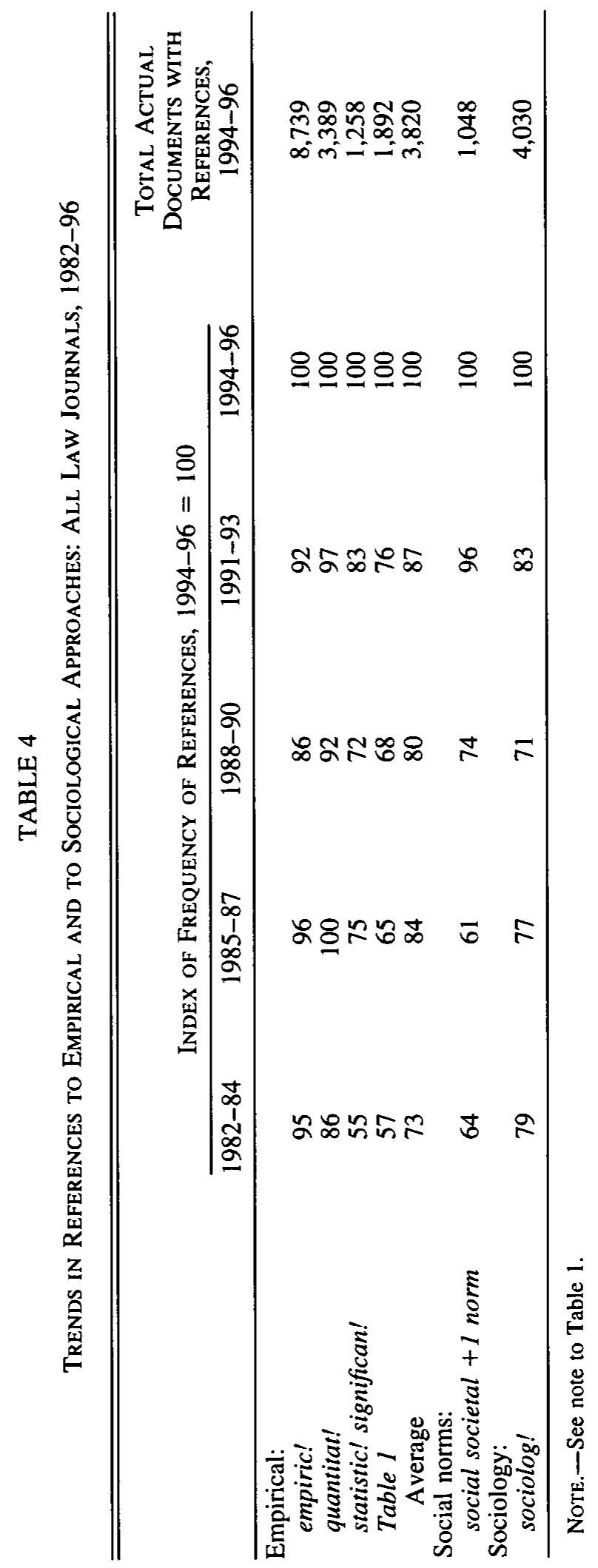

HeinOnline -- 29 J. Legal Stud. 5292000 
sociolog! (a general proxy) and for social norm or societal norm (a more specific one) rise by about one-third from $1988-90$ to $1994-96 .{ }^{26}$ In sum, while there is no bandwagon toward social science, that perspective is broadly embraced and more than holding its own.

\section{E. Other "Law and" Approaches}

Findings on the trajectories of a miscellany of other approaches to legal analysis are presented in Table 5. Contrary to my own impression that legal history has been coming into fashion, the average of the indexes for the three proxies for work in a historical vein is essentially flat from 1982 to 1996. Also flat are the indexes for natural law and metaphysic!, the two proxies used for traditional legal philosophy.

Several other approaches, on the other hand, are on the upswing. Supporting the notion that legal scholars increasingly are turning to psychology, ${ }^{27}$ the index for cognitive doubles between the beginning and the end of the study period. The most notable skyrocket in Table 5 is civic republicanism, a normative political ideal revivified in the 1980s.

\section{F. Comparisons of Actual Numbers of JLR References in 1994-96}

To this point I have focused mainly on the direction of trends in interest in the various ideas and approaches, not on the absolute levels of interest in them. The right-most columns of Tables 1-5 display the actual number of JLR documents referring to each proxy in 1994-96. Table 5, reveals, for example, that there were 429 references to civic-republican!, the lowest number for any proxy other than the 196 for intersectionality (a marker for Critical Race Theory). ${ }^{28}$ Even if civic republicanism is soaring, it remains an uncommon theme among legal scholars.

It is risky to place much stock in the actual numbers of references to particular proxies. That transaction! cost! won 2,836 references in 199496, compared to 1,287 for post-modern! and to 945 for critical legal studies, may have more to do with the vagaries of authors' usages than with the relative popularity of the perspectives associated with these phrases. How-

${ }^{26}$ My attempts to find a workable proxy for "law and society" scholarship were unavailing. These failures may have stemmed from the great diversity of work done by the scholars who group themselves under the law-and-society moniker. On this intellectual approach, see Duxbury, supra note 24, at 440-46; Lawrence M. Friedman, The Law and Society Movement, 38 Stan. L. Rev. 763 (1986).

${ }^{27}$ As predicted in Mark I. Satin, Law and Psychology: A Movement Whose Time Has Come, 1994 Ann. Surv. Am. L. 581.

${ }^{28}$ With these two exceptions, I rejected any proxy that appeared in fewer than 500 documents in 1994-96. See supra text around note 6. 


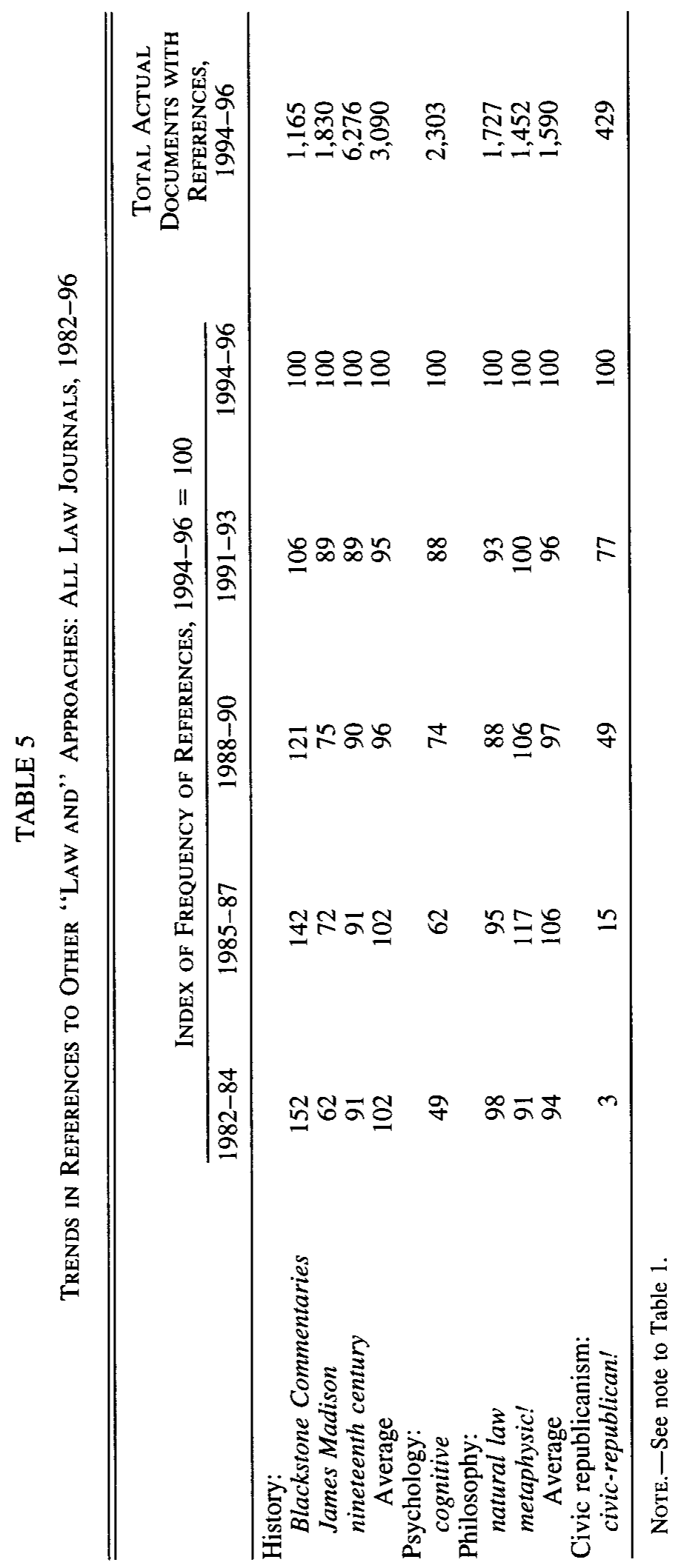

HeinOnline -- 29 J. Legal Stud. 5312000 
ever, these particular statistics do seem robust enough to caution, say, editorialists for the Wall Street Journal, against proclaiming that antiestablishment ideas now dominate the pages of American law reviews.

\section{ARe Documents in Leading Journals Different?}

The contents of prime law journals might differ systematically from the contents of average ones. It is conceivable, for instance, that authors of documents in leading journals have disproportionately abandoned doctrinal analysis or especially embraced law and economics.

To investigate this issue I analyzed documents published in the flagship student-edited law journals of five leading law schools-Chicago, Columbia, Harvard, Stanford, and Yale. ${ }^{29}$ Westlaw offers an individual database for each of these five journals. Searches for all 35 proxies were conducted in these individual databases, and the findings were summed. The sums were used to provide the entries for "leading journals" in Tables 6-11. As before, absolute counts were indexed so that $1994-96=100$, except that the numbers for leading journals were adjusted by a "leading-journal deflator," not by the rare-word deflator. The leading-journal deflator eliminates the small distortions that otherwise would be created by the minor variations in the number of documents Westlaw offers for these five journals for the period $1982-96 .^{30}$

\section{A. Trends in Doctrinal Analysis and Law and Economics in Leading Law Journals}

Table 6 displays the time trends of appearances in leading journals of documents containing proxies for either doctrinal analysis or law and economics. For most entries the trend lines point in the same direction as do their counterparts for all JLR journals. (Compare Table 6 with Tables 1 and 2.) Many of the slopes are similar as well. For example, the proxies for law and economics generally exhibit the same moderate rise in the leading journals that they exhibit in all journals.

\footnotetext{
${ }^{29}$ The ranking of law schools understandably is deeply contested. I restricted the "leading" category to a mere five schools in order to limit the administrative burden of searching databases. The five law schools I chose generally have been at the top of the U.S. News \& World Report's Academic Reputation Rankings throughout the 1990s. See Richard Schmalbeck, The Durability of Law School Reputation, 48 J. Legal Educ. 568, 570-72 (1998). Precedent also favors selection of the journals of these five schools; Landes and Posner picked them when undertaking a similar investigation. See Landes \& Posner, supra note 4, at 399.

${ }^{30}$ For details, see the Appendix. The JLR has full coverage of the Columbia, Harvard, and Yale journals after 1981 and of Chicago's after 1982. The JLR's coverage of the Stanford Law Review is selected in 1982 and becomes full in 1984.
} 


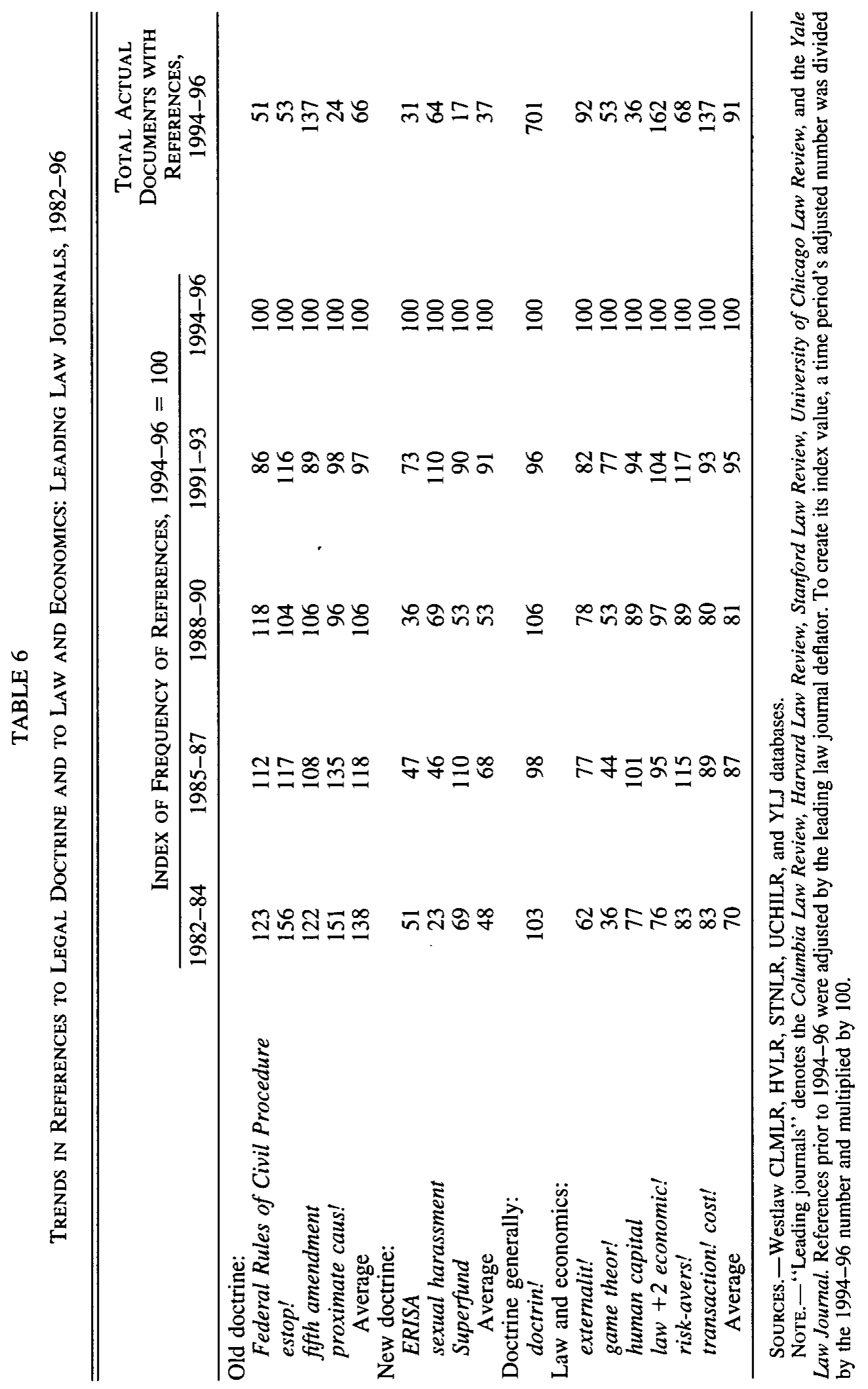


But some differences stand out. Note that sexual harassment peaks in the leading journals in 1991-93 but not in all journals until 1994-96. Perhaps the student editors of leading journals were unusually quick to react to the Anita Hill-Clarence Thomas hearings of 1991.

More significant, in the leading journals the average of the indexes for proxies for "old doctrine" falls from 138 to 100 over the course of 198296 , while in all journals the drop is a mere 108 to 100 . References in 198296 to new doctrine also rise less sharply in leading journals (from 48 to 100) than in all journals (from 28 to 100). These results support John Langbein's impression that the trend line for doctrinal analysis is less favorable in leading journals than in law journals generally. ${ }^{31}$ On the other hand, in 1994-96 about 70 percent $(701$ out of 1,017$)$ of the documents published in the leading journals contained doctrin!, a percentage that holds firm between 1982-84 and 1994-96. And only about 33 percent ${ }^{32}$ of documents in all JLR journals published in 1994-96 contain doctrin!, a percentage less than half as large as that for leading journals. ${ }^{33}$ It certainly is possible that, page for page, leading journals are less doctrinal than other law journals. The data do not speak to that question. What is clear is that doctrinal references remain rife not only in journals generally but in leading journals as well.

\section{B. Trends in Other Intellectual Approaches in Leading Journals}

Table 7 indicates the direction of movement in the leading journals of the aggregate indexes for all 15 intellectual approaches. ${ }^{34}$ These data provide the basis for calculations, presented in Tables 8-11 below, that compare intellectual trends in leading journals with those in nonleading journals.

In leading journals "old doctrine"' is the only approach that declines throughout the 1982-96 period. Critical Legal Studies both booms more

${ }^{31}$ See supra note 11.

${ }^{32}$ This percentage can be computed from a numerator found in Table 1 and a denominator found in Table Al.

${ }^{33}$ This result mainly stems from the much greater median length, in 1994-96, of documents in leading journals. All else being equal, the longer a document, the higher the probability that any search term is contained within it. The median length of a sample of all JLR documents fell from 63 Westlaw pages to 32 Westlaw pages between 1982-84 and 199496. See supra note 10. My sampling of documents in the leading journals revealed no comparable falloff in length; the median lengths there were 55 Westlaw pages in 1982-84 and 58 Westlaw pages in 1994-96. (The mean lengths of documents in leading journals were 86 pages in 1982-84 and 87 pages in 1994-96.) In sum, in the mid-1990s leading journal documents had a median length almost twice that of all JLR documents.

${ }^{34}$ In contrast to Table 6, Table 7 does not report the results obtained for each individual proxy. 


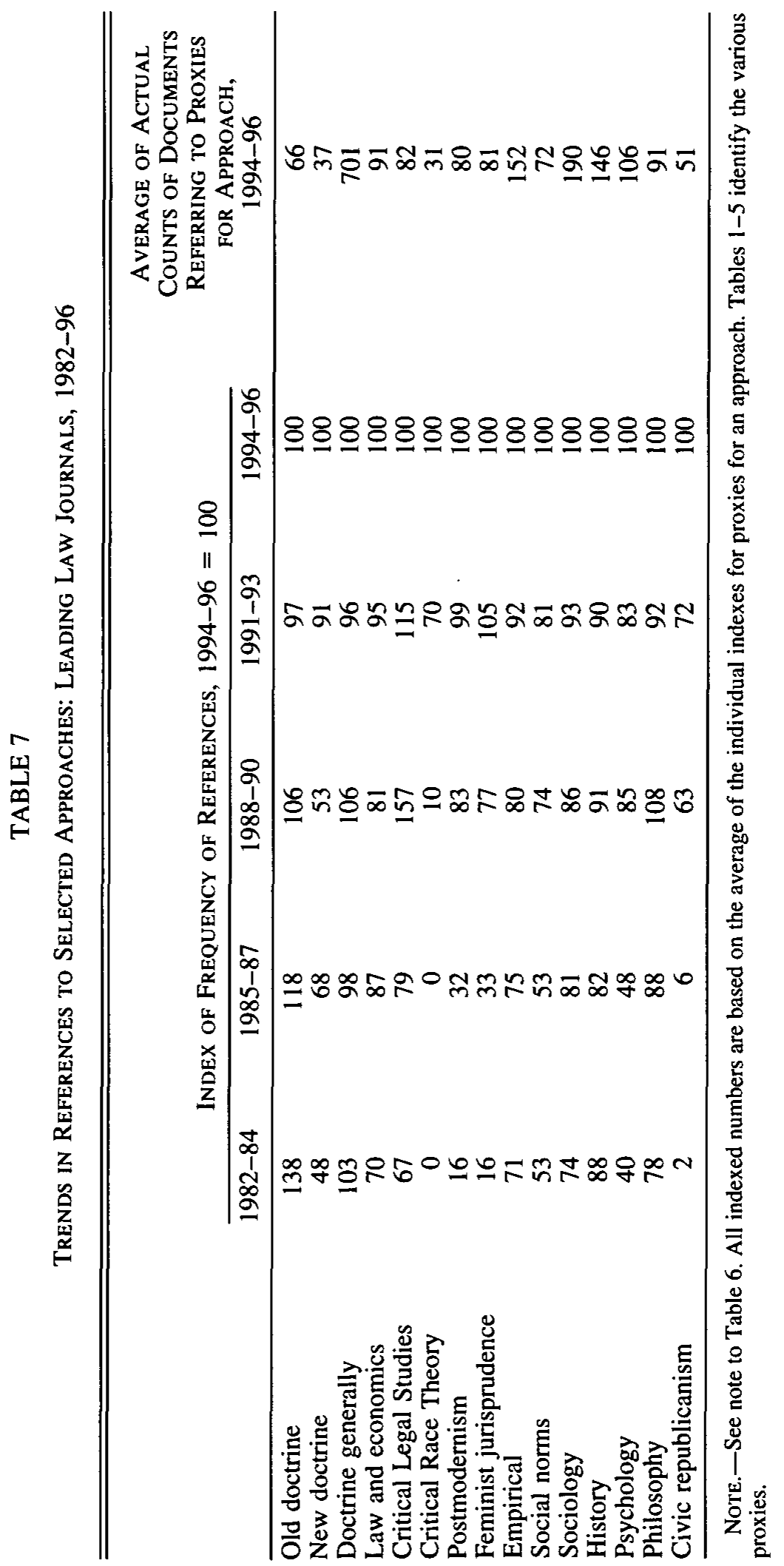


TABLE 8

For Doctrinal and Law-and-Economic Approaches, Average Document Count per Proxy as a Percentage of Total Documents: Comparison of LEADING AND Nonleading LaW Journals, 1982-96

\begin{tabular}{|c|c|c|c|c|c|}
\hline & \multicolumn{5}{|c|}{$\%$ of All Documents } \\
\hline & $1982-84$ & $1985-87$ & $1988-90$ & $1991-93$ & $1994-96$ \\
\hline \multicolumn{6}{|l|}{ Old doctrine: } \\
\hline Leading journals (\%) & 8.6 & 7.4 & 7.0 & 6.2 & 6.5 \\
\hline Nonleading journals (\%) & 7.8 & 5.6 & 6.3 & 5.8 & 4.7 \\
\hline \multirow{2}{*}{\multicolumn{6}{|c|}{ New doctrine: }} \\
\hline & & & & & \\
\hline Leading journals (\%) & 1.4 & 2.1 & 2.1 & 3.6 & 3.7 \\
\hline Nonleading journals (\%) & 1.3 & 2.2 & 3.1 & 3.6 & 3.2 \\
\hline Ratio leading/nonleading & [1.1] & [.9] & {$[.7]$} & {$[1.0]$} & {$[1.2]$} \\
\hline \multicolumn{6}{|l|}{ Doctrine generally: } \\
\hline Leading journals (\%) & 70.8 & 67.7 & 73.0 & 66.4 & 68.9 \\
\hline Nonleading journals (\%) & 56.8 & 40.6 & 41.1 & 40.0 & 34.3 \\
\hline Ratio leading/nonleading & {$[1.2]$} & {$[1.7]$} & {$[1.8]$} & {$[1.7]$} & {$[2.0]$} \\
\hline \multicolumn{6}{|l|}{ Law and economics: } \\
\hline Leading journals (\%) & 6.5 & 8.0 & 7.5 & 8.6 & 9.0 \\
\hline Nonleading journals (\%) & 2.3 & 1.7 & 1.9 & 2.1 & 2.2 \\
\hline Ratio leading/nonleading & {$[2.8]$} & [4.6] & {$[4.0]$} & [4.1] & {$[4.1]$} \\
\hline
\end{tabular}

sharply and busts more precipitously in the leading journals than it does in all journals (compare Table 3 with Table 7). Philosophy, which is flat in all journals, prospers in the leading journals between 1982-84 and 1988-90 but then plateaus.

\section{Trends in the Percentage of Documents Referring to Various Approaches: Leading Journals Compared to Nonleading Journals}

Tables 5 and 7 indicate that both leading journals and all journals have experienced roughly the same rate of increase in references to civicrepublican!. In 1994-96, however, the percentage of documents in leading journals containing civic-republican! was over eight times the analogous percentage for all journals. In short, a comparison of indexed trend lines fails to reveal differences in the absolute amount of attention that leading and nonleading journals have been paying to various legal approaches.

Tables 8-11 remedy this shortcoming. All were derived in the same fashion. The percentage shown in each time slot was computed by dividing the average actual (that is, unadjusted) count for the (one or more) proxies for 
TABLE 9

For Antiestablishment Approaches, Average Document Count per Proxy as a Percentage of Total Documents: Comparison of Leading and NONLEADING LAW JOURNALS, 1982-96

\begin{tabular}{lccccc}
\hline \hline & \multicolumn{5}{c}{$\%$ of ALL DocuMENTs } \\
\cline { 2 - 6 } & $1982-84$ & $1985-87$ & $1988-90$ & $1991-93$ & $1994-96$ \\
\hline Critical Legal Studies: & & & & & \\
$\quad$ Leading journals (\%) & 5.4 & 6.4 & 12.6 & 9.3 & 8.1 \\
$\quad$ Nonleading journals (\%) & .9 & 1.3 & 1.5 & 1.6 & 1.2 \\
$\quad$ Ratio leading/nonleading & {$[6.0]$} & {$[5.0]$} & {$[8.2]$} & {$[5.9]$} & {$[6.6]$} \\
Critical Race Theory: & & & & & \\
$\quad$ Leading journals (\%) & .0 & .0 & .3 & 2.5 & 3.0 \\
$\quad$ Nonleading journals (\%) & .0 & .0 & $.0^{\mathrm{a}}$ & .3 & .5 \\
$\quad$ Ratio leading/nonleading & N.A. & N.A. & {$[12.4]$} & {$[8.0]$} & {$[5.9]$} \\
Postmodernism: & & & & & \\
$\quad$ Leading journals (\%) & 1.3 & 2.5 & 6.5 & 7.7 & 7.8 \\
$\quad$ Nonleading journals (\%) & .2 & .5 & .8 & 1.5 & 1.7 \\
$\quad$ Ratio leading/nonleading & {$[6.9]$} & {$[4.7]$} & {$[7.9]$} & {$[5.2]$} & {$[4.6]$} \\
Feminist jurisprudence: & & & & & \\
$\quad$ Leading journals (\%) & 1.2 & 2.7 & 6.3 & 8.4 & 8.0 \\
$\quad$ Nonleading journals (\%) & .5 & .6 & .9 & 1.8 & 2.0 \\
$\quad$ Ratio leading/nonleading & {$[2.4]$} & {$[4.5]$} & {$[6.7]$} & {$[4.7]$} & {$[3.9]$} \\
\hline
\end{tabular}

NotE.-Ratios are in brackets. See also note to Table 8; N.A. means not applicable.

actual percentage is .028 .

TABLE 10

For Empirical and Sociological Approaches, Average Document Count per Proxy as a Percentage of Total Documents: Comparison of LEADING AND NoNLEAding LaW JouRNALS, 1982-96

\begin{tabular}{|c|c|c|c|c|c|}
\hline \multirow[t]{2}{*}{ - } & \multicolumn{5}{|c|}{$\%$ of All Documents } \\
\hline & $1982-84$ & $1985-87$ & $1988-90$ & $1991-93$ & 1994-96 \\
\hline \multicolumn{6}{|l|}{ Empirical: } \\
\hline Leading journals (\%) & 11.4 & 11.7 & 12.8 & 13.7 & 14.9 \\
\hline Nonleading journals (\%) & 6.4 & 4.6 & 4.5 & 5.1 & 5.2 \\
\hline Ratio leading/nonleading & {$[1.8]$} & [2.5] & [2.8] & [2.7] & {$[2.9]$} \\
\hline \multicolumn{6}{|l|}{ Social norms: } \\
\hline Leading journals (\%) & 3.8 & 3.8 & 5.2 & 5.7 & 7.1 \\
\hline Nonleading journals (\%) & 1.1 & .8 & 1.0 & 1.4 & 1.4 \\
\hline Ratio leading/nonleading & [3.4] & [4.9] & [5.2] & [4.0] & [5.1] \\
\hline \multicolumn{6}{|l|}{ Sociology: } \\
\hline Leading journals (\%) & 13.8 & 15.1 & 16.1 & 17.4 & 18.7 \\
\hline Nonleading journals (\%) & 5.9 & 3.8 & 3.8 & 4.9 & 5.5 \\
\hline Ratio leading/nonleading & [2.4] & [3.9] & [4.2] & [3.6] & [3.4] \\
\hline
\end{tabular}

NOTE.-Ratios are in brackets. See also note to Table 8. 
TABLE 11

For Other "Law and" Approaches, Average Document Count per Proxy as a PERCENTAGe of Total Documents: Comparison of Leading aND NoNLEADING LAW JouRnals, 1982-96

\begin{tabular}{|c|c|c|c|c|c|}
\hline & \multicolumn{5}{|c|}{$\%$ of All Documents } \\
\hline & $1982-84$ & $1985-87$ & $1988-90$ & $1991-93$ & 1994-96 \\
\hline \multicolumn{6}{|l|}{ History: } \\
\hline Leading journals (\%) & 11.5 & 10.9 & 13.2 & 12.4 & 14.4 \\
\hline Nonleading journals (\%) & 5.4 & 3.8 & 3.9 & 4.1 & 4.2 \\
\hline Ratio leading/nonleading & [2.1] & [2.9] & [3.4] & [3.0] & [3.4] \\
\hline \multicolumn{6}{|l|}{ Psychology: } \\
\hline Leading journals (\%) & 4.2 & 5.0 & 8.9 & 8.7 & 10.4 \\
\hline Nonleading journals (\%) & 2.2 & 1.9 & 2.3 & 3.0 & 3.1 \\
\hline Ratio leading/nonleading & [1.9] & [2.7] & [3.8] & [2.9] & [3.3] \\
\hline \multicolumn{6}{|l|}{ Philosophy: } \\
\hline Leading journals (\%) & 6.8 & 7.8 & 9.5 & 8.0 & 8.9 \\
\hline Nonleading journals (\%) & 2.7 & 2.1 & 2.0 & 2.2 & 2.1 \\
\hline Ratio leading/nonleading & [2.5] & [3.7] & [4.7] & [3.6] & [4.2] \\
\hline \multicolumn{6}{|l|}{ Civic republicanism: } \\
\hline Leading journals (\%) & .1 & .3 & 3.2 & 3.6 & 5.0 \\
\hline Nonleading journals (\%) & $.0^{\mathrm{a}}$ & .1 & .2 & .4 & .5 \\
\hline Ratio leading/nonleading & {$[7.2]$} & [3.6] & {$[15.1]$} & {$[8.3]$} & {$[9.1]$} \\
\hline
\end{tabular}

NOTE.-Ratios are in brackets. See also note to Table 8.

"Actual percentage is .015 .

the approach by the number of total documents for that time slot. To illustrate, consider the number in the last column of the first row of Table 8 (6.5 percent). The numerator used to generate that result was 66 , the average of the number of documents that searches for the four proxies for old doctrine generated in the leading law journals in 1994-96. ${ }^{35}$ The denominator was 1,017 , the total number of JLR documents in the leading law journals in the same time period. ${ }^{36}$ Any particular percentage in Tables 8-11 reveals little by itself. For instance, if negligen! had been used in lieu of proximate caus!, the percentage of leading journal documents referring to "old doc-

${ }^{35}$ See line 5 of Table 6.

${ }^{36}$ See Table A1. This method is sensitive to changes in database size over time because both the numerator and the denominator used to compute a percentage are derived from actual document counts for the time slot in question. More worrisome is the sharp reduction between 1982 and 1996 in the mean and median lengths of documents published in the nonleading journals. See supra note 10 (reporting trends in lengths of documents in all JLR journals). As a result, all else being equal, the chance that the average document in a nonleading journal would contain any discrete word or phrase fell over this period. My failure to account for declining document length in nonleading journals lends a downward bias to the ratios presented in Tables 8-11 in the columns associated with the early time slots. 
trine" doubtless would have been significantly higher than 6.5 percent in 1994-96.

Far more revealing is the ratio between (1) the percentage of leading journal documents that refer to a particular approach and (2) the analogous percentage for nonleading journals. Tables $8-11$ present these ratios for each approach in each time period. An intellectual approach with an unusually high ratio is particularly in vogue in the leading journals, as opposed to law journals generally. The highest ratios in the columns for the 199496 period are associated with, in descending order, civic republicanism (9.1), Critical Legal Studies (6.6), Critical Race Theory (5.9), social norms (5.1), postmodernism (4.6), philosophy (4.2), and law and economics (4.1). The lowest ratios are for new doctrine (1.2), old doctrine (1.4), doctrine generally (2.0), empirical work (2.9), and psychology (3.3). Observe that the ratio for each of the 15 approaches exceeds 1.0 in 1994-96. This stems from the greater average length and intellectual complexity of documents in leading journals.

The ratios indicate the relative priorities of the student editors of the five law journals included in the "leading" category. As Langbein suspected, in 1994-96 these editors, compared with the editors of nonleading journals, generally favored high theory over doctrinal work. Indeed, this tilt is evident throughout the time period examined. Even in 1982-84 the highest ratios were garnered by civic republicanism (7.2), postmodernism (6.9), and Critical Legal Studies (6.0), and the lowest ratios, as in 1994-96, were associated with the three doctrinal approaches.

Tables 8-11 do suggest some changes over time, however. The data provide modest support for the notion that a rising intellectual approach to legal problems tends first to emerge in the leading law reviews and then diffuse to law journals generally. ${ }^{37}$ For example, Table 9 reveals that leading law journals were among the first to favor works referring to postmodernism and feminism (both evident by 1988-90), and also Critical Race Theory (evident by 1991-93). In the case of all three of these antiestablishment approaches the nonleading journals thereafter began to catch up, in part because all three approaches began to show signs of plateauing in the leading journals. In the most recent period, 1994-96, history, psychology, social norms, and civic republicanism began to garner larger numbers of refer-

\footnotetext{
${ }^{37}$ Indeed, this is why the most selective law journals accurately can be labeled leading. On the diffusion of new ideas within social groups, see, generally, Everett M. Rogers, Diffusion of Innovations (4th ed. 1995). Economists recently have begun to study fads and cascades - the most rapid forms of diffusion. See, for example, B. Douglas Bernheim, A Theory of Conformity, 102 J. Pol. Econ. 841 (1994); Sushil Bikhchandani et al., A Theory of Fads, Fashions, Custom, and Cultural Change as Informational Cascades, 100 J. Pol. Econ. 992, 1002-3 (1992).
} 
ences in leading journals (but not in nonleading journals). Neophyte scholars, take notice.

Do the editors of leading journals also jump off intellectual bandwagons before editors of nonleading journals do? The leading/nonleading ratio for Critical Legal Studies falls from 8.2 in 1988-90 to 6.6 in 1994-96, a scrap of evidence in support of this view.

\section{CONClusion}

This study is premised on the proposition that a word or phrase can serve as a plausible proxy for a complex legal idea or intellectual approach. If the premise is sound, the ever-growing electronic databases will have opened up astonishing opportunities for quantitative work on the history of legal thought. ${ }^{38}$

The methods employed could be extended in a number of dimensions. Subsequent researchers could experiment with different proxies, not to mention different deflators. Post-1996 data could be marshaled to test, for example, whether the various antiestablishment approaches are avoiding the bust that afflicted Critical Legal Studies after 1992. Like most citation analysts, I did not distinguish derogatory references from positive ones. A more painstaking investigator could sample citations across time to look for trends in the incidence in negative citations to the fields of, say, law and economics, Critical Legal Studies, and feminist jurisprudence.

Simple modifications of the experimental design would better expose how ideas diffuse and dissipate. In this initial foray I identified a mere five law journals as "leading" and compared their contents with those of more than 600 others. A subtler classification of journals might have unveiled far more. The diffusion of legal ideas from the academy to other wings of the legal profession (and vice versa) could be explored by means of searches in other databases. How do the ideas that appear in the publications included in Westlaw's LAWPRAC (a database for legal practitioners) vary from those in the relatively academic journals included in JLR? How often, if at all, do authors who write for practitioners use critical race theory, cognitive, or natural law? How often do judicial opinions refer to transaction! cost!, statistic! significan!, or post-modern!?

This article has neglected the dynamics of one of the latest fads in legal scholarship: citation analysis itself. Here are some possible proxies for

\footnotetext{
${ }^{38}$ Two of the leading works on the intellectual history of the legal academy are Duxbury, supra note 24 , and Schlegel, supra note 24 . Neither exploits data available in electronic databases.
} 
tracking interest in the approach to which this symposium is devoted: SSCI, citations $w / 2$ number, and fred +2 shapiro.

\section{APPENDIX}

\section{Deflating a Database Whose Size Changes over Time}

This study reports the results of searches conducted in Journals and Law Reviews (JLR), an electronic database within Westlaw. Counts of the total number of documents appearing in JLR were retrieved by means of searches taking the form of \#and \& da(aft 1981 \& bef 1985). (Placing the \# sign before a search term allows a user to bypass Westlaw's error message and complete a search even if it may retrieve an unusually large number of documents.) As Table A1 indicates, the number of documents in JLR grew about ninefold between 1982-84 and 1994-96. Searches such as ci(hvlr) \& da(aft $1981 \&$ bef 1985) were used to count documents in each of the five leading journals. Counts of documents in nonleading journals were derived by subtraction.

The entries in the first row of Table A1 were used to create a leading law journal deflator. In order that $1994-96=1.00$, this deflator was generated by dividing each entry for a time period by the entry for 1994-96. The results are presented in the bottom row of Table A2. This deflator was applied to adjust counts obtained from searches in the leading journals. This approach assumes that the probability that a document in a leading journal was "concept laden" did not change between 1982 and 1996.

Choosing a deflator for all JLR documents was a more difficult task. As the text accompanying notes 7-10 explains, when Westlaw expanded JLR after 1984 it disproportionately added (1) documents from journals less professorial than those it had covered in the early years and (2) student work and book reviews from journals from which it had previously covered only articles. For both reasons, the typical JLR document became less concept laden between 1982-84 and 1994-96. As a result, if a particular concept were to have been of constant appeal to law journal authors throughout this period, one would expect the number of documents referring to that concept to rise, not ninefold, but by a somewhat smaller multiplier.

Experiments were conducted with deflators based on three different measures of concept ladenness. All three are designed to be independent of the proxies that later might be employed for particular legal concepts. The first candidate, the rare-word deflator, is based on the notion that the trend in the numbers of documents containing a widely recognized but rarely used English word should be similar to the trend in the number of documents referring to a proxy for a intellectual approach.

TABLE A1

NuMBER OF DocUmENTS IN JLR (Undeflated)

\begin{tabular}{lcrrrr}
\hline \hline & $1982-84$ & $1985-87$ & $1988-90$ & $1991-93$ & $1994-96$ \\
\hline In five “leading"' journals & 957 & 1,037 & 1,012 & 994 & 1,017 \\
In "nonleading" joumals & 6,866 & 19,862 & 28,644 & 44,391 & 70,341 \\
\cline { 2 - 6 } Total (all JLR) & 7,823 & 20,899 & 29,656 & 45,385 & 71,358 \\
\hline
\end{tabular}


TABLE A2

DEFLATION INDEXES FOR JLR $(1994-96=1.00)$

\begin{tabular}{lccccc}
\hline \hline & $1982-84$ & $1985-87$ & $1988-90$ & $1991-93$ & $1994-96$ \\
\hline Rare-word deflator & 5.96 & 3.37 & 2.26 & 1.44 & 1.00 \\
Common-word deflator & 6.76 & 3.29 & 2.21 & 1.46 & 1.00 \\
University deflator & 5.37 & 2.80 & 2.08 & 1.74 & 1.00 \\
Raw count of JLR documents & 9.12 & 3.41 & 2.41 & 1.57 & 1.00 \\
Leading law journal deflator & .94 & 1.02 & 1.00 & .98 & 1.00 \\
\hline
\end{tabular}

The document counts for 10 specific rare words, each used in less than 1 percent of JLR documents, were combined to generate this index. The second candidate, the common-word deflator, was similarly inspired, except that it is based on trends in the counts of documents containing citations to words each common enough to appear in about 30 percent of JLR documents. Finally, to have a proxy for the number of documents citing academic law journals, I experimented with a university deflator based on trends in the number of documents referring to the abbreviated name of some randomly selected universities that publish one or more law journals, for example, cornell, harv, hastings, notre dame, $u+2$ pitt, and vand. For all three candidates, the deflator was calculated by summing the document counts for each of its components and then deflating that sum. The results for the various deflators are presented in Table A2. Figure A1 graphically portrays the first four deflators in Table A2-the ones relevant to the task of neutralizing the growth in the number of JLR documents.

To appraise the relative merits of the three main candidates, each was applied to deflate the trends in references to a large sampling of proxies for the various legal approaches. Each candidate's results were portrayed in the form of dozens of line graphs, superimposed on each other in a single figure. The university deflator was rejected because its application tended to produce a upward "bump" in references to nearly all proxies for the period 1991-93, a time when Westlaw was add-

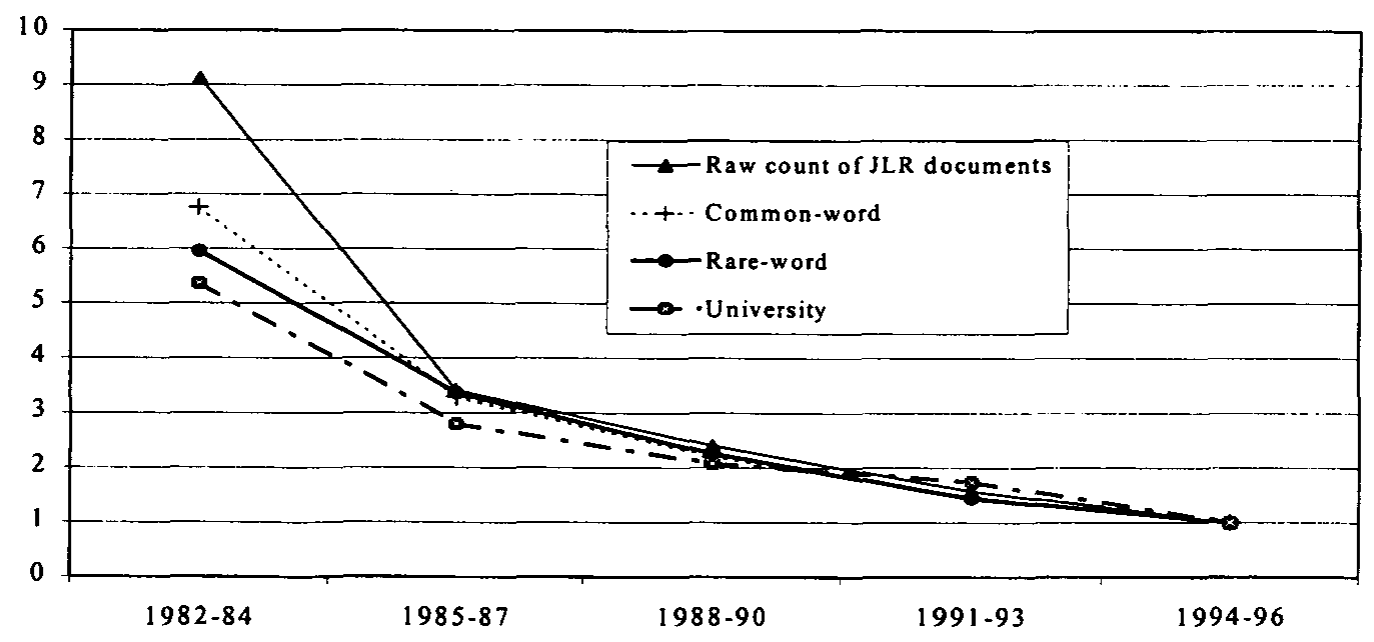

FIGURE A1.-Comparison of four indexes for deflating JLR document counts 
ing many non-university-affiliated law journals to JLR. Both the rare-word and common-word deflators generated clusters of lines that generally lacked collective peaks and valleys. Because most proxies appear relatively rarely, I chose the rareword deflator on the ground that it is the conceptually sounder of the two.

The 10 search terms that make up the rare-word deflator are baffling, castigated, doctrinaire, honed, intermix!, lukewarm, masquerade, quiescen!, rummag!, and seasonabl!. A potential search term was rejected if it is associated with a particular ideology or method. Each term was checked to ensure that it seldom appears in case names and titles of much-cited articles. Each of the 10 words used to construct the deflator appears in between 150 and 250 JLR documents published in 199496. The sum of the number of documents referring to these 10 words rises about sixfold from 1982-84 to 1994-96. (The number of documents containing quiescen! rises just over fourfold; at the other extreme is lukewarm, up almost 11 -fold.)

The rare-word deflator reported in Table A2 was calculated in January 1999. After that date Westlaw may add more documents published in 1982-96. Because a citation analyst is able to conduct a search only in a contemporary database, the values shown for the rare-word deflator are likely to become increasingly unreliable as time passes. By following the methods described an investigator could update the deflator in about 2 hours. 
HeinOnline -- 29 J. Legal Stud. 5442000 